\title{
Chemometrically Assisted RP-HPLC Method Development for Efficient Separation of Ivabradine and its Eleven Impurities
}

\author{
Jovana Tomić ${ }^{1}$, Branka Ivković ${ }^{1}$, Slavica Oljačić ${ }^{1}$, Katarina Nikolić ${ }^{1}$, Nevena Maljurić \\ Ana Protić ${ }^{2}$ and Danica Agbaba ${ }^{*}$ \\ 'University of Belgrade, Faculty of Pharmacy, Department of Pharmaceutical Chemistry, Vojvode Stepe 450, 11221 Belgrade, Serbia \\ University of Belgrade, Faculty of Pharmacy, Department of Drug Analysis, Vojvode Stepe 450, 11221 Belgrade, Serbia
}

Received: 21 May 2019; accepted: 03 June 2019

\begin{abstract}
The aim of this study was to develop a novel reversed-phase high-performance liquid chromatography (RP-HPLC) method for efficient separation of ivabradine and its 11 impurities. Similar polarity of impurities in the sample mixture made method optimization challenging and accomplishable only when different chemometric tools, such as principal component analysis (PCA), Box-Behnken design (BBD), and desirability function as a multicriteria approach, were employed. The presence of 3 positional isomers (impurities III, V, and VI), keto-enol tautomerism of impurity VII, and diastereoisomers of impurity X made separation of this complex mixture even more challenging. Chromatographic retention parameters obtained with the mobile phase consisting of $30 \mathrm{mM}$ phosphate buffer and acetonitrile $(80: 20, \mathrm{v} / \mathrm{v})$ on four different RP-HPLC columns at varying $\mathrm{pH}$ values $(3.0,4.0$, and 5.0) were subjected to the PCA analysis to select the column with the most appropriate selectivity. Then the column temperature, $\mathrm{pH}$ of the aqueous component of mobile phase, phosphate buffer molarity and the organic solvent content in the mobile phase were estimated employing BBD. Valid and reliable mathematical models towards resolution of twelve critical peak pairs were obtained. After determination of the desirability making criteria for all responses, desirability functions were established and used in optimization. The proposed optimal chromatographic conditions included the Zorbax Eclipse Plus C18 chromatographic column $(100 \times 4.6 \mathrm{~mm}, 3.5 \mu \mathrm{m})$, the column temperature of $34^{\circ} \mathrm{C}$, the mobile phase flow rate of $1.6 \mathrm{~mL} \mathrm{m^{-1 }}$ and the UV detection at $220 \mathrm{~nm}$. The mobile phase consisted of the $28 \mathrm{mM}$ phosphate buffer at $\mathrm{pH} 6.0$ and acetonitrile $(85: 15, \mathrm{v} / \mathrm{v})$. Separation of one pair of positional isomers was not achieved, so methanol was added to the organic part of mobile phase in small increments with the optimal ratio of methanol to acetonitrile $59: 41, \mathrm{v} / \mathrm{v}$. The overall organic component of the mobile phase also increased to $18 \%$, accelerating the chromatographic analysis.
\end{abstract}

Keywords: Ivabradine, principal component analysis, Box-Behnken design, isocratic elution RP-HPLC, diastereoisomers

\section{Introduction}

Ivabradine is chemically $3-(3-\{[((7 \mathrm{~S})-3,4-$ dimethoxybicyclo[4.2.0]octa-1,3,5-trien-7-yl)methyl] methylamino\} propyl)1,3,4,5-tetrahydro-7,8-dimethoxy-2H-3-benzazepin-2-one hydrochloride (Figure 1). It is a novel heart beats lowering agent, with a demonstrated efficacy in treatment of chronic stable angina pectoris and myocardial ischemia with an optimal tolerability profile, because of its selective interaction with pacemaker channels [1]. The mechanism of action of ivabradine is based on reduction of the rate of pacemaker activity in the sinoatrial node by selective inhibition of the f-current (If). The named current is involved in generating an early phase of spontaneous diastolic depolarization in the pacemaker cells, enabling reduced frequency of the action potential initiation and the lower heart rate [2-4].

One of the potential synthesis pathways of ivabradine is reductive coupling of the reduced form of the derivative azepane ((7,8-dimethoxy-1,3-dihydro-2H-3-benzazepine-2-one-3-yl)-2(1,2-dioxolan-2yl)ethane) and butamine hydrochloride (impurity I). Butamine hydrochloride along with impurities II, III, IV, V, VI, VII, VIII, and IX is recognized as impurity related to the synthesis pathway, but also as the degradation impurity.

*Author for correspondence: Department of Pharmaceutical Chemistry, University of Belgrade-Faculty of Pharmacy, Vojvode Stepe 450, 11000 Belgrade, Serbia; E-mail: danica.agbaba@pharmacy.bg.ac.rs; Phone: +381113951 339.
On the contrary, impurities X and XI are defined only as the potential degradation products of ivabradine. Chemical structures of all the investigated impurities are shown in Figure 1.

During the literature survey, a few analytical and bioanalytical methods for determination of ivabradine were found. Papers dealing with biological samples mostly dealt with the high-performance liquid chromatography (HPLC) and the ultra-high performance liquid chromatography (UHPLC) methods using the different detection techniques, in order to determine ivabradine and its low concentrated metabolites in urine and plasma [5-9]. Furthermore, a limited number of studies were devoted to the development of analytical methods capable of determination of ivabradine, its impurities, and/or the degradation products. Namely, only two papers dealing with optimization of the stability-indicating high-performance thin-layer chromatographic method (HPTLC), reversed-phase high-performance liquid chromatographic method (RP-HPLC), and spectrophotometric method for the separation of ivabradine and its potential degradation products formed under acidic and basic conditions were reported $[10,11]$. However, no comprehensive evaluation of ivabradine's stability or assessment of the efficiency of the method separation efficiency regarding all the degradation products was provided. Nevertheless, the stress degradation was conducted in one study and used for stability estimation and determination of ivabradine's degradation pathway. Its sensitivity to acidic and basic

This is an open-access article distributed under the terms of the Creative Commons Attribution-NonCommercial 4.0 International License (https://creativecommons.org/licenses/by-nc/4.0/), which permits unrestricted use, distribution, and reproduction in any medium for non-commercial purposes, provided the original author and source are credited, a link to the CC License is provided, and changes - if any - are indicated. 
<smiles>COc1cc2c(cc1OC)CC(=O)N(CCCN(C)C[C@H]1Cc3cc(OC)c(OC)cc31)CC2</smiles>

Ivabradine<smiles>COc1cc2c(cc1OC)C(=O)N(CCCN(C)C[C@H]1Cc3cc(OC)c(OC)cc31)CC2</smiles>

Impurity III<smiles>COc1cc2c(cc1O)CCN(CCCN(C)C[C@H]1Cc3cc(OC)c(OC)cc31)C(=O)C2</smiles>

Impurity V<smiles>COc1cc2c(cc1OC)C(=O)N(CCCN(C)CC1Cc3cc(OC)c(OC)cc3[C@@H]1O)CC2</smiles>

Impurity VII<smiles>COc1cc2c(cc1OC)CC(=O)N(CCCN(C)C[C@H]1Cc3cc(OC)c(OC)cc31)C=C2</smiles>

Impurity IX<smiles>COc1cc(CC=O)c(CCNCCCN(C)C[C@H]2Cc3cc(OC)c(OC)cc32)cc1OC</smiles><smiles>CNCC1Cc2cc(OC)c(OC)cc21</smiles>

Butamine hydrochloride
Impurity I<smiles>CNCCCN1CCc2cc(OC)c(OC)cc2CC1=O</smiles>

Impurity II<smiles>COc1cc2c(cc1OC)CC(=O)N(CCCNC[C@H]1Cc3cc(OC)c(OC)cc31)CC2</smiles>

Impurity IV<smiles>COc1cc2c(cc1O)CC(=O)N(CCCN(C)C[C@H]1Cc3cc(OC)c(OC)cc31)CC2</smiles>

Impurity VI<smiles></smiles>

Impurity VIII<smiles>COc1cc2c(cc1OC)CC(=O)N(CCC[N+](C)(O)C[C@H]1Cc3cc(OC)c(OC)cc31)CC2</smiles>

Impurity $\mathbf{X}$

Impurity XI

Figure 1. Chemical structures of ivabradine and its impurities and the degradation products

degradation was confirmed, together with degradation pathway dependence on the influence of hydrochloric or sulfuric acid [12]. The gradient elution HPLC method was proposed for determination of ivabradine and its 5 potential degradation products. Therefore, on the basis of a limited number of the reported methods along with the fact that present pharmacopeia does not contain a monograph of ivabradine, a comprehensive method that could enable retention evaluation of ivabradine along with its impurities, and the degradation products is urgent in this field. Furthermore, due to the different synthesis pathways, there are numbers of different impurities possibly appearing in ivabradine, whose physicochemical characterization and relation to the HPLC retention are required. Therefore, in this paper, evaluation of retention and the isocratic elution HPLC method development was studied. Separation of the proposed complex mixture was challenging, if we consider similar polarities of ivabradine and its degradation products together with the very similar physicochemical properties of the three positional isomers (impurities III, V, and VI). Through a thorough evaluation of the impurities' structures, it was noticed that keto-enol tautomerism can be expected, when dealing with impurity VII. Furthermore, impurity $\mathrm{X}$ represents N-oxide, a substance with 2 chiral centers. Having 2 chiral centers pointed out that formation of two diastereoisomers can occur. Diasteroisomers, unlike enantiomers, exhibit different physicochemical characteristics enabling their separation on the analytical HPLC columns using a standard mixture of the organic solvent and water as the mobile phase.

Thus, in order to obtain an efficient separation of this complex analytical mixture, the chemometric approach was applied at different stages of method development, and it included principal component analysis (PCA) for the selection of the columns, the Box-Behnken design (BBD), and the desirability function for method optimization.

\section{Materials and Methods}

Chemicals. Standard samples of ivabradine hydrochloride and its 11 impurities were kindly donated by Les Laboratoires Servier (Paris, France). Potassium hydroxide (Actavis d.o.o., Leskovac, Serbia), potassium dihydrogen phosphate (J.T. Baker, Deventer, Holland), and ortho-phosphoric acid $85 \%$ (Merck, Darmstadt, Germany) were of analytical grade. The HPLC-grade acetonitrile (Merck, Darmstadt, Germany) and methanol (J.T. Baker B.V., Deventer, The Netherlands) were used for the analysis. Deionized water was produced using a water purification system Simplicity 185 from Millipore (Billerica, MA, USA) at $18.2 \mathrm{M} \Omega \mathrm{cm}$ resistivity.

Chromatographic Conditions and Equipment. Chromatographic analysis was performed with use of an Agilent Technologies (Palo Alto, CA, USA) HP 1200 chromatograph equipped with an on-line degasser, a binary pump, a column oven, a diode array detector, and a Rheodyne 
$20-\mu \mathrm{L}$ loop injector. Data were acquired by means of the HP ChemStation software. Chromatographic separation was performed on several chromatographic columns: Zorbax Eclipse XDB Phenyl $(4.6 \times 250 \mathrm{~mm}, 5 \mu \mathrm{m})$ column (Agilent Technologies, Santa Clara, CA, USA), Zorbax Eclipse plus C18 $(4.6 \times 250 \mathrm{~mm}, 5 \mu \mathrm{m})$ column (Agilent Technologies, Santa Clara, CA, USA), Zorbax Eclipse plus C8 $(4.6 \times 250 \mathrm{~mm}$, $5 \mu \mathrm{m}$ ) column (Agilent Technologies, Santa Clara, CA, USA), and Synergy 4u Polar-RP 80A $(4.6 \times 250$ mm, $4 \mu \mathrm{m})$ column (Phenomenex, Torrance, CA, USA).

Final separation was achieved with the Zorbax Eclipse plus C18 column $(4.6 \times 250 \mathrm{~mm}, 5 \mu \mathrm{m})$ termostatted at $34{ }^{\circ} \mathrm{C}$. The analyses were carried out in the isocratic elution mode with mobile phase A, consisting of the $28 \mathrm{mM}$ potassium phosphate buffer at $\mathrm{pH} 6$ adjusted with ortho-phosphoric acid, and mobile phase $\mathrm{B}$, consisting of the acetonitrile-methanol mixture $(41: 59, v / v)$. The A/B ratio was $82: 18, v / v$. The flow rate of the mobile phase was set to $1.6 \mathrm{~mL} / \mathrm{min}$. The detection wavelength was $220 \mathrm{~nm}$.

Preparation of Mobile Phase and Standard Solutions. Stock solutions of ivabradine and the investigated impurities were prepared by dissolving an appropriate amount of standard substance in methanol, to obtain a final concentration of $100 \mu \mathrm{g} / \mathrm{mL}$ for each compound. Due to the known photosensitivity of ivabradine, all solutions were protected from daylight and stored in amber glass vials within a temperature range from 2 to $8^{\circ} \mathrm{C}$.

Working samples were prepared by dissolving a proper amount of the stock solutions of ivabradine and its impurities in the mobile phase composed of A (potassium dihydrogen phosphate) and B (acetonitrile-methanol, 41:59, v/v) in a ratio of $81: 18(v / v)$, to obtain final concentration of $200 \mu \mathrm{g} \mathrm{mL}^{-1}$ for ivabradine hydrochloride and $4 \mu \mathrm{g} \mathrm{mL}^{-1}$ for each individual impurity.

The content of acetonitrile in the mobile phase $(15-20 \%$, $v / v)$, the phosphate buffer concentration $(20-40 \mathrm{Mm})$, the $\mathrm{pH}$ value of the aqueous phase (4-6), and the column temperature $\left(30-40{ }^{\circ} \mathrm{C}\right)$ varied according to the experimental plan defined by the Box-Behnken design. The $\mathrm{pH}$ value of the aqueous phase was adjusted by addition of ortho-phosphoric acid to obtain $\mathrm{pH}$ 6. Further, the ratio of acetonitrile to methanol $(41: 59, v / v)$ was adjusted using the one-factor-at-a-time approach (OFAT). Portions of the mobile phase were prepared in the amounts sufficient for daily use to ensure their stability. The mobile phase was filtered through a nylon membrane filter with a $0.45-\mu \mathrm{m}$ pore size (Agilent Technologies, Santa Clara, USA) and degassed in an ultrasonic bath prior to use.

Software. The Design Expert 11.0.0. (Modeling and Design) 10.1 v. program (Stat-Ease $^{\circledR}$, Minneapolis, Minnesota) was used to obtain the plan of experiments and for statistical analysis of the obtained results. PCA was performed employing Statistica 13.5 (TIBCO software, CA, USA) $[13,14]$.

PCA Analysis. PCA is a reliable and commonly used multivariate statistical procedure converting a set of possibly correlated variables into a set of linearly uncorrelated variables called principal components (PCs). The number of PCs is lower than or equal to the number of the original variables [15-20]. Through a few PCs only, variability in the data set is assessed. Vectors recognized as eigenvectors of the matrix are used to define each PC. Variance along the vector is an eigenvalue, and it corresponds with the percentage of variance modeled by the corresponding PC. The maximum variance of the data is usually covered with the first PC, while the total variance is the sum of the variances of the original variables. To visualize the relationship between the objects and variables, the score and loading plots are constructed.

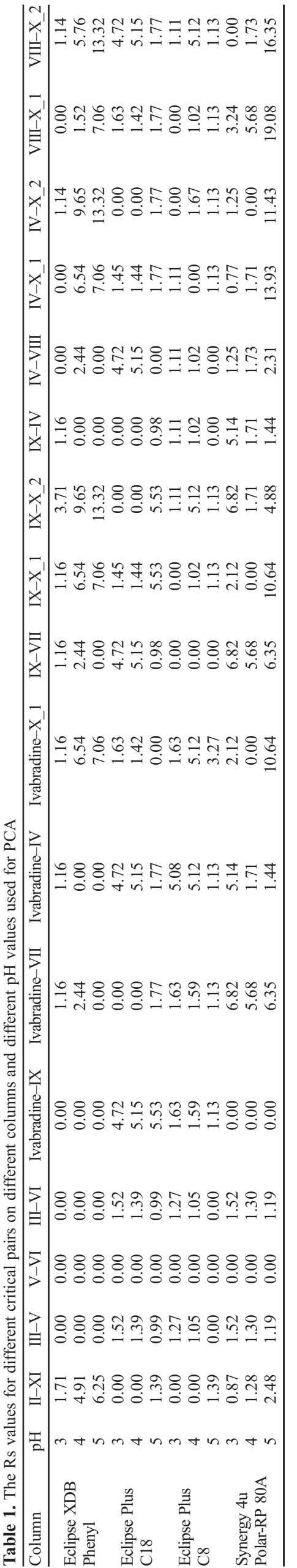




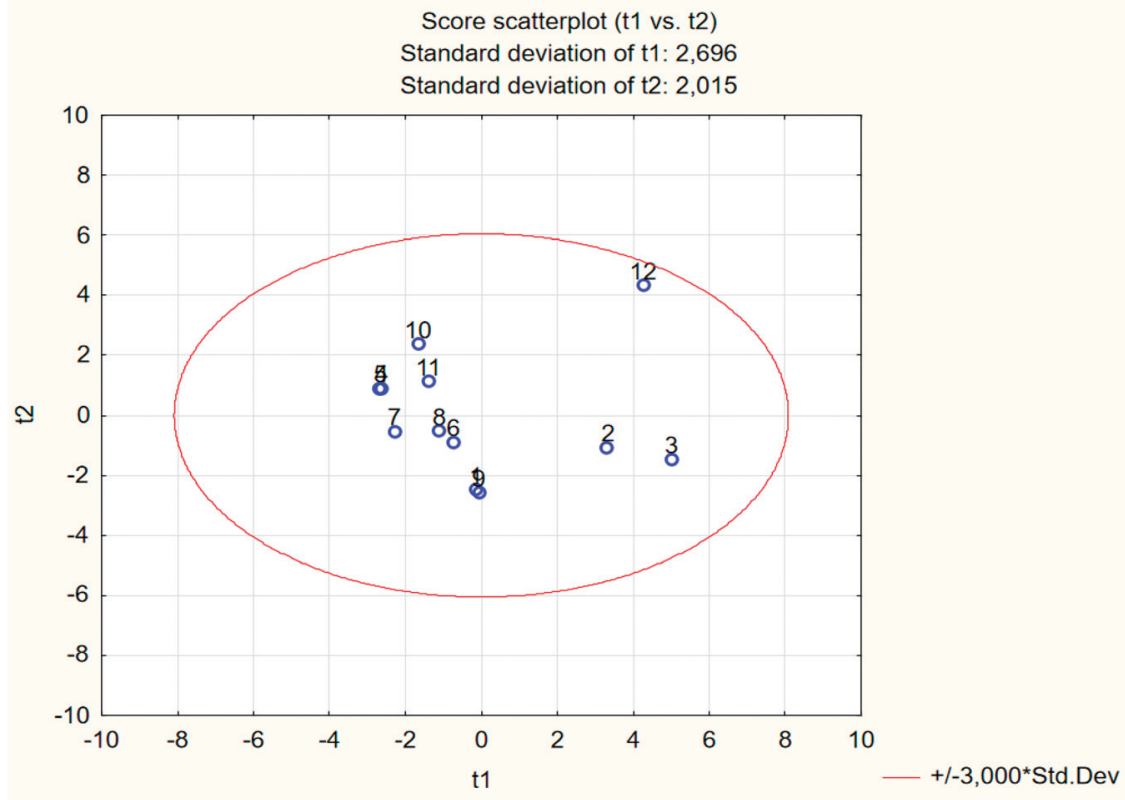

Figure 2. Score plot of the first two PC vectors

Response Surface and Multivariate Response Methodology. When only a few responses are being analyzed, the optimal region is easy to be located by mathematical equations and the 3D diagrams [21]. On the contrary, when several responses are to be optimized simultaneously, the multicriteria decision making approach (MCDM) is recommended. This approach allows identification of the best solution in the most efficient way from creation a local optimal solution to a group of different objectives. Each objective may contribute in a positive or a negative way to the final solution [22]. The path of the steepest ascent, the desirability function, and the mathematical programming are different approaches implied with MCDM. The path of the steepest ascent is applicable to the linear models only. As linear models are not usually related to the response surface methodology (RSM), this approach has not been applied. Further, when dealing with the systems where only one response could be marked as the most important, a mathematical programming approach can be taken.
Since separation of complex mixtures could not be accomplished towards only one response, this approach was not suitable. Consequently, the desirability functions applicable to both linear and non-linear models and with optimization capability towards an unlimited number of responses were selected. These functions are based on the idea that a quality of the process that has multiple quality characteristics, with one of them outside of some "desired" limits, is completely unacceptable. For each response, values of the desirability function can appear between 0 and 1, where 0 represents completely undesired values of response, and 1 represents a completely desirable or ideal response value [23]. Before starting the optimization process, the priorities and desires for each response must be defined. These priorities are defined through the responses' bounds, goals, and weights $\left(w t_{i}\right)$. For different goals, transformation could be one-sided (maximization and minimization) and two-sided (target value and in range). The weights emphasize a goal, an upper or lower

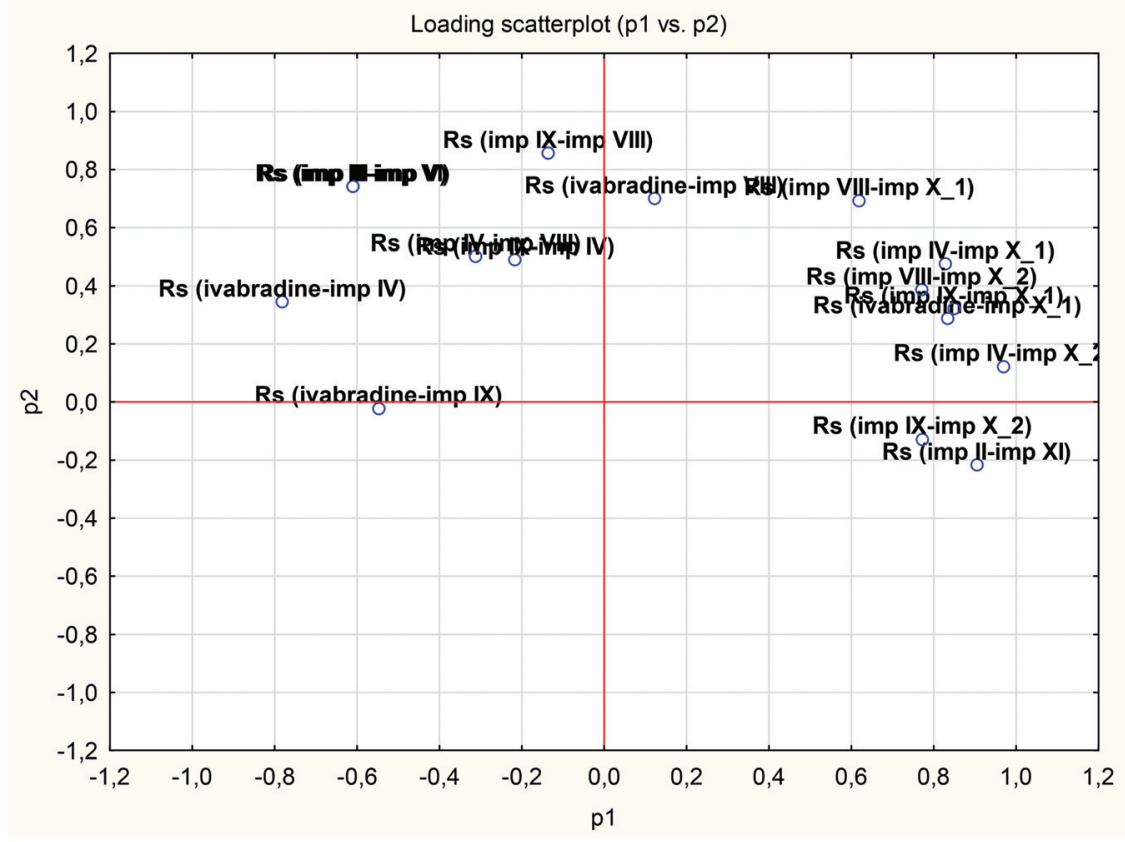

Figure 3. Loading plot of the first two PC vectors 
Table 2. Investigated variables and their domains

\begin{tabular}{lccc}
\hline Investigated variable & \multicolumn{3}{c}{ Defined level of variables } \\
\cline { 2 - 4 } & -1 level & 0 level & +1 level \\
\hline $\mathrm{pH}$ of water phase & 4 & 5 & 6 \\
Column temperature $\left({ }^{\circ} \mathrm{C}\right)$ & 30 & 35 & 40 \\
Acetonitrile $(\%)$ & 15 & 17.50 & 20 \\
Concentration of phosphate buffer $(\mathrm{mM})$ & 20 & 30 & 40 \\
\hline
\end{tabular}

bounds, or a target value. With $w t_{i}$ of 1 , the desirability function $\left(d_{i}\right)$ can vary from 0 to 1 in a linear way, while approaching a desired value. The weights higher than 1 stronger emphasize the goal, whereas the weights lower than 1 give less emphasis to the goal, and in both cases, $d_{i}$ varies in a non-linear way [21].

The desirability values are calculated using Eq. (1), when the goal is maximization:

$$
d_{i}=\left[\frac{Y_{i}-\mathrm{Low}_{i}}{\operatorname{High}_{i}-\mathrm{Low}_{i}}\right]^{\mathrm{wt}_{i}} \quad \operatorname{Low}_{i}<Y_{i}<\operatorname{High}_{i}
$$

where $Y_{i}$ is the predicted response using the fitted model, and the highest and the lowest values are obtained for the response, respectively, and $w t_{i}$ is the weight.

The desirability values are calculated using Eq. (2), when the goal is minimization:

$$
d_{i}=\left[\frac{\operatorname{High}_{i}-Y_{i}}{\operatorname{High}_{i}-\operatorname{Low}_{i}}\right]^{\mathrm{wt}_{i}}
$$

Eq. (3) is used, when the goal is a target value, where the desirability ramps are formed similar to a maximum on the way up, and a minimum on the way down:

$$
\left.\begin{array}{ccc}
d_{i}=0, & z a & Y_{i}<\text { Low }_{i} \\
d_{i}=\left(\frac{Y_{i}-\text { Low }_{i}}{\text { target }_{i}-\text { Low }_{i}}\right)^{w t_{i}}, & z a & \text { Low }_{i}<Y_{i}<\text { target }_{i} \\
d_{i}=\left(\begin{array}{c}
Y_{i}-\operatorname{High}_{i} \\
\text { High }_{i}-\operatorname{target}_{i}
\end{array}\right)^{w t_{j}}, \quad z a & t_{i}<Y_{i}<u_{i} \\
d_{i}=0 & z a & Y_{i}>u_{i}
\end{array}\right\}
$$

where $\operatorname{target}_{i}$ is the target value.

For a goal within a range, Eqs. (4) and (5) are used:

$$
d_{i}=0, \text { for } Y_{i}=\operatorname{Low}_{i}
$$

$$
d_{i}=1, \text { for }^{L} w_{i}<Y_{i}<\operatorname{High}_{i}
$$

When individual desirability functions $d_{i}$ are obtained, the overall desirability function $(D)$ is further estimated. The $D$ value can range from 0 for the totally undesirable responses to 1 , when all responses are desirable. In this paper, the Derringer desirability function is used, where the $D$ function is calculated, using Eq. (6):

$$
D=\left(d_{1}^{r t_{1}} d_{2}^{r t_{2}}, \ldots, d_{I}^{r t_{I}}\right)^{1 / \sum^{r t_{i}}}
$$

\begin{tabular}{|c|c|c|c|c|c|c|c|c|c|c|c|c|c|c|c|}
\hline \multicolumn{4}{|c|}{$\begin{array}{l}\text { Investigated variables } \\
\text { within their domains }\end{array}$} & \multicolumn{12}{|c|}{ Responses } \\
\hline$\overline{\mathrm{pH}}$ & $T$ & $\mathrm{ACN}$ & Buffer & $\begin{array}{c}\mathrm{Rs} \\
(\mathrm{I} / \mathrm{XI})\end{array}$ & $\begin{array}{c}\text { Rs } \\
(\mathrm{III} / \mathrm{V})\end{array}$ & $\begin{array}{c}\mathrm{Rs} \\
(\mathrm{V} / \mathrm{VI})\end{array}$ & $\begin{array}{c}\mathrm{Rs} \\
(\mathrm{III} / \mathrm{VI})\end{array}$ & $\begin{array}{c}\mathrm{Rs} \\
\left(\mathrm{IVB} / \mathrm{X}_{-} 1\right)\end{array}$ & $\begin{array}{c}\mathrm{Rs} \\
\left(\mathrm{IVB} / \mathrm{X} \_2\right)\end{array}$ & $\begin{array}{c}\text { Rs } \\
\text { (IX/VIII) }\end{array}$ & $\begin{array}{c}\mathrm{Rs} \\
\left(\mathrm{IX} / \mathrm{X} \_2\right)\end{array}$ & $\begin{array}{c}\mathrm{Rs} \\
\text { (IX/IV) }\end{array}$ & $\begin{array}{c}\mathrm{Rs} \\
(\mathrm{IV} / \mathrm{VIII})\end{array}$ & $\begin{array}{c}\text { Rs } \\
\left(\mathrm{IV} / \mathrm{X}_{-} 1\right)\end{array}$ & $\begin{array}{c}\mathrm{Rs} \\
\left(\mathrm{IV} / \mathrm{X} \_2\right)\end{array}$ \\
\hline 4 & 30 & 17.5 & 30 & 1.46 & 0.74 & 0.00 & 1.19 & 4.82 & 4.14 & 0.00 & 1.52 & 1.52 & 1.52 & 0.42 & 0.00 \\
\hline 6 & 30 & 17.5 & 30 & 12.06 & 0.63 & 1.83 & 0.88 & 5.90 & 5.14 & 1.26 & 14.89 & 5.61 & 4.21 & 5.90 & 5.14 \\
\hline 4 & 40 & 17.5 & 30 & 1.56 & 1.40 & 0.00 & 1.4 & 3.55 & 3.21 & 1.68 & 0.00 & 0.00 & -0.11 & 0.95 & 0.00 \\
\hline 6 & 40 & 17.5 & 30 & 15.31 & 1.21 & 2.25 & 1.18 & 9.55 & 7.93 & 0.00 & 14.58 & 7.58 & 7.58 & 7.37 & 5.92 \\
\hline 5 & 35 & 15.0 & 20 & 7.77 & 1.11 & 1.11 & 0.32 & 2.17 & 3.12 & 0.00 & 1.10 & 0.00 & 1.01 & 1.97 & 1.10 \\
\hline 5 & 35 & 20.0 & 20 & 2.20 & 1.28 & 0.00 & 1.28 & 0.00 & 0.00 & 1.26 & 3.62 & 1.26 & 0.00 & 2.29 & 2.29 \\
\hline 5 & 35 & 15.0 & 40 & 6.05 & 0.54 & 0.00 & 0.00 & 1.97 & 3.07 & 0.00 & 1.13 & 1.52 & 1.52 & 3.69 & 4.69 \\
\hline 5 & 35 & 20.0 & 40 & 1.26 & 0.75 & 0.00 & 0.00 & 0.91 & 0.00 & 0.00 & 1.87 & 0.00 & 0.00 & 2.92 & 1.87 \\
\hline 4 & 35 & 17.5 & 20 & 1.98 & 1.35 & 0.20 & 1.35 & 4.93 & 5.79 & 1.22 & 2.21 & 2.21 & 2.57 & 0.95 & 0.00 \\
\hline 6 & 35 & 17.5 & 20 & 15.42 & 1.10 & 2.56 & 1.11 & 6.74 & 7.03 & 0.29 & 13.3 & 7.10 & 7.10 & 6.39 & 5.56 \\
\hline 4 & 35 & 17.5 & 40 & 1.29 & 0.76 & 0.00 & 0.60 & 2.10 & 3.73 & 0.00 & 1.61 & 1.61 & 1.61 & 1.61 & 0.00 \\
\hline 6 & 35 & 17.5 & 40 & 12.92 & 0.62 & 1.88 & 0.48 & 7.31 & 6.50 & 0.00 & 12.30 & 7.65 & 7.65 & 8.71 & 7.55 \\
\hline 5 & 30 & 15.0 & 30 & 6.80 & 0.58 & 0.39 & 0.89 & 1.94 & 2.77 & 0.74 & 1.85 & 3.25 & 1.61 & 1.52 & 1.06 \\
\hline 5 & 40 & 15.0 & 30 & 7.70 & 1.26 & 0.40 & 0.84 & 2.47 & 3.37 & 0.00 & 0.54 & 0.00 & 0.00 & 1.19 & 2.73 \\
\hline 5 & 40 & 20.0 & 30 & 2.21 & 1.30 & 0.00 & 1.33 & 0.95 & 0.00 & 1.45 & 4.08 & 1.45 & 0.00 & 3.22 & 2.06 \\
\hline 4 & 35 & 15.0 & 30 & 4.38 & 0.99 & 0.00 & 0.00 & 4.40 & 6.46 & 0.00 & 0.51 & 1.62 & 1.62 & 0.00 & 1.37 \\
\hline 6 & 35 & 15.0 & 30 & 22.10 & 0.76 & 2.93 & 2.03 & 7.54 & 7.78 & 1.21 & 15.47 & 8.42 & 9.01 & 6.79 & 5.85 \\
\hline 4 & 35 & 20.0 & 30 & 0.01 & 1.12 & 0.00 & 2.41 & 1.76 & 3.13 & 1.71 & 0.00 & 1.08 & 1.36 & 1.36 & 0.00 \\
\hline 6 & 35 & 20.0 & 30 & 7.51 & 1.19 & 1.19 & 0.00 & 6.51 & 5.35 & 0.00 & 11.85 & 5.00 & 5.00 & 4.62 & 4.62 \\
\hline 5 & 30 & 17.5 & 20 & 3.70 & 0.70 & 0.69 & 0.96 & 0.00 & 1.38 & 0.00 & 2.47 & 0.00 & 0.00 & 2.03 & 2.47 \\
\hline 5 & 40 & 17.5 & 20 & 5.66 & 1.57 & 0.71 & 1.08 & 1.31 & 1.24 & 1.43 & 4.19 & 1.43 & 0.00 & 2.75 & 2.75 \\
\hline 5 & 30 & 17.5 & 40 & 2.48 & 0.35 & 0.00 & 0.00 & 0.00 & 1.13 & 0.00 & 2.02 & 0.93 & 0.00 & 2.62 & 2.02 \\
\hline 5 & 40 & 17.5 & 40 & 2.45 & 0.98 & 0.00 & 0.18 & 0.00 & 0.00 & 0.00 & 1.62 & 0.00 & 0.00 & 3.14 & 1.62 \\
\hline 5 & 35 & 17.5 & 30 & 6.75 & 1.05 & 0.10 & 0.45 & 0.55 & 0.36 & 0.01 & 2.59 & 0.53 & 0.01 & 3.59 & 2.60 \\
\hline 5 & 35 & 17.5 & 30 & 2.99 & 0.99 & 0.01 & 0.40 & 1.09 & 0.00 & 0.21 & 3.42 & 0.12 & 0.15 & 3.00 & 3.02 \\
\hline 5 & 35 & 17.5 & 30 & 3.76 & 1.20 & 0.20 & 0.38 & 0.00 & 0.71 & 0.00 & 2.17 & 0.21 & 0.02 & 2.83 & 2.17 \\
\hline
\end{tabular}

where $r$ represents the importance of each response, and it gets the values from 1 to 5 . Value 1 is assigned to the responses that are of lower importance, and the higher the value of $r$, the greater is the importance of the response.

Table 3. The Box-Behnken design plan of experiments for four variables and resolutions of the critical peak pairs as the investigated responses ( $\mathrm{pH}=$ value of water phase; $T=$ column temperature $\left({ }^{\circ} \mathrm{C}\right) ; \mathrm{ACN}-$ percentage of acetonitrile as an organic mobile phase modifier $(\%)$, Buffer $=$ concentration of the phosphate buffer in aqueous mobile phase $(\mathrm{mM})$ ) 
The greatest benefit of the desirability functions is reducing the multicriteria problem to a single criterion problem that can be optimized in a simpler way [21, 24-26].

\section{Results and Discussion}

Generally, separation in RP-HPLC strongly depends on the column type and selectivity, physicochemical properties of the investigated analytes, and chromatographic conditions, and for this reason, the first step in the separation of ivabradine and its 11 impurities was to select an appropriate column. For an efficient selection of the proper RP-HPLC column, PCA was employed. At the next step, the experimental domains of the most influential chromatographic parameters were determined and optimized using BBD as one of the response surface designs. The obtained mathematical equations were applied to the Derringer's desirability function, while resolutions of all critical peak pairs were marked as system's responses. When the optimal separation conditions were determined, an additional optimization by the one-factor-at-a-time (OFAT) approach was performed to adjust the ratio of acetonitrile and methanol in the mobile phase, since the results of the desirability function approach indicated that this was the only variable left to be optimized.

In the course of the preliminary experiments, the keto-enol tautomers of impurity VII and the diastereoisomers of impurity $\mathrm{X}$ were separated under some of the examined experimental conditions. Further, in order to distinguish the isomers, the keto-enol tautomers were labeled as VII 1 and VII 2 , respectively, while the diastereoisomers were labeled as $\mathrm{X}_{1}$ and $\mathrm{X}_{2}$.

Classification of RP-HPLC Columns towards Resolution of Ivabradine and its Eleven Impurities. PCA is taking 4 different RP-HPLC columns at varying mobile phase buffer $\mathrm{pH}$ values $(3.0,4.0$, and 5.0) into the account. The subject matter of PCA is resolution (Rs) between the closely eluting components. Different elution order of the investigated analytes was observed under the different buffer $\mathrm{pH}$ values, and the resolution data used in PCA is shown in Table 1. None of the examined columns independent of the employed buffer $\mathrm{pH}$ values allow separation of impurities V and VI. Furthermore, there were several critical peak pairs, whose separation was hardly achieved on the investigated columns. The following peak pairs were found as critical: impurity III and impurity V, impurity III and impurity VI, ivabradine and impurity IX, ivabradine and impurity VIII, ivabradine and impurity IV, impurity VIII and impurity IV, impurity IX and impurity IV, and impurity IX and impurity VIII.

The analysis showed that $94.03 \%$ total variation could be explained with 5 components, each of them explaining 45.43, $25.37,14.19,4.87$, and $4.17 \%$, respectively. The first 2 PCs accounting for $70.8 \%$ of cumulative variation were retained for further analysis.

To properly analyze the results, the score (Figure 2) and loading plots (Figure 3 ) were obtained. The score plot shows location of the objects in the multivariate space of the first 2 PC score vectors, while the loading plot visualizes the pattern of correlation between the variables, showing the influence of the variables on the model, as well as their mutual correlation. The chromatographic parameters which are more distant from the axis origin have a greater impact on positioning of the RPHPLC columns of similar characteristics.

When analyzing the obtained score and loading plots, there is a rule stating that the samples in the right part of the score plot have high values for the variables placed in the right part of the loading plot. In addition, the samples in the left part of the score plots, regardless of their bottom or top placement, have high values of the variables placed in the left part of the

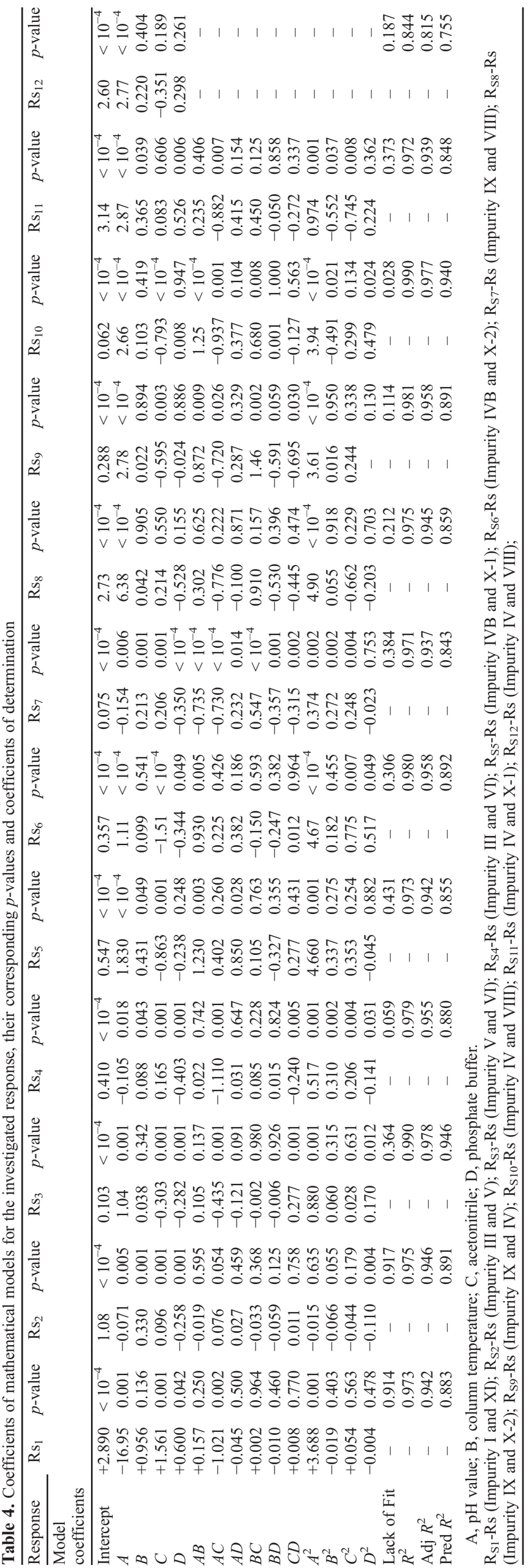



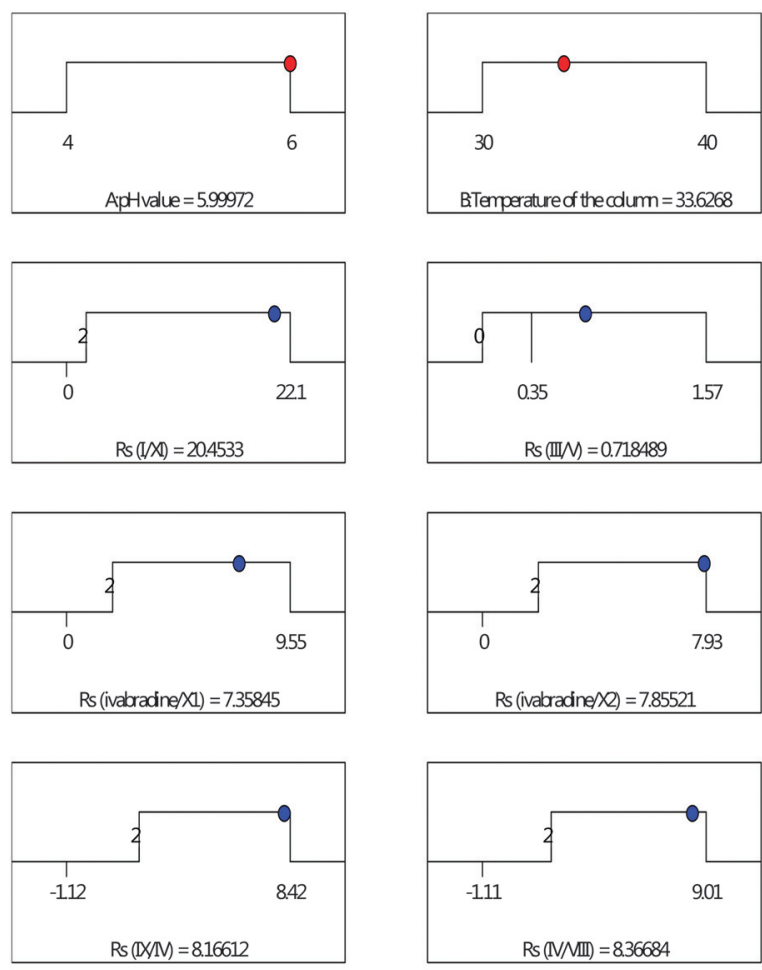
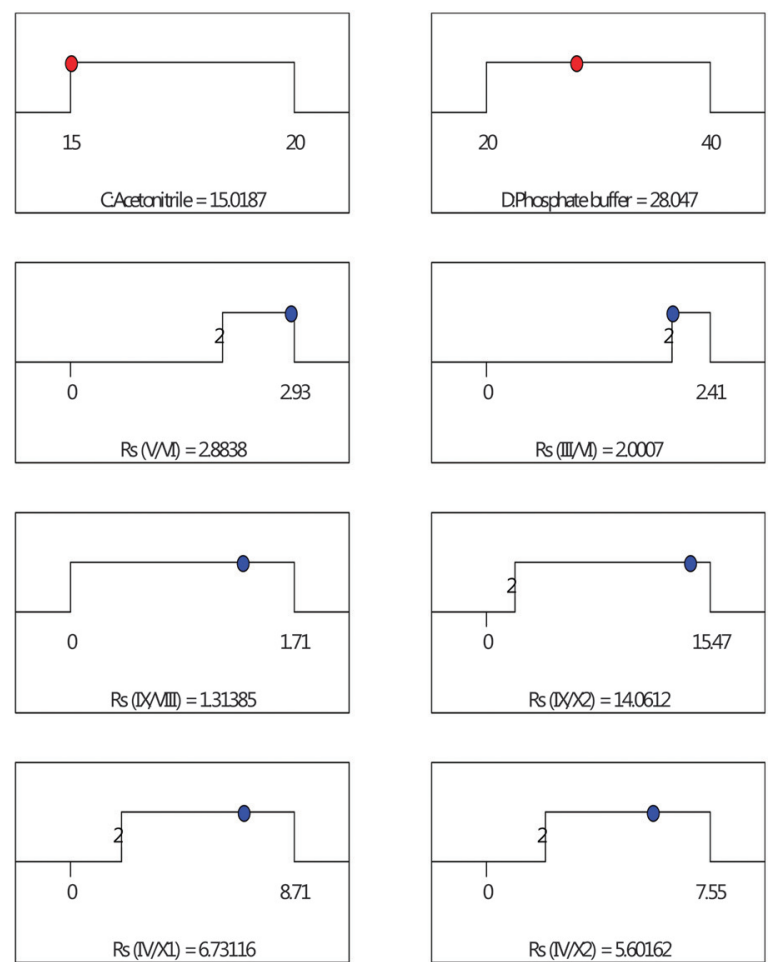

Desirability $=1000$

Solution 6 aut of 23

Figure 4. Bar plots for the proposed optimal chromatographic conditions and the resolution values for all twelve critical peak pairs

loading plot. The score plot (Figure 2) shows that the RPHPLC columns are classified into 4 groups. The type of the RP-HPLC column together with the buffer $\mathrm{pH}$ value under investigation is arranged close to each other on the basis of similar characteristics in terms of the critical pair resolution factors.

The Eclipse Phenyl column at the buffer $\mathrm{pH}$ values of 4 and 5 is placed in the lower right part of the score plot, enabling resolution of the following pairs: impurity II-impurity $\mathrm{XI}$ and impurity IX-impurity $\mathrm{X}_{2}$. However, these pairs were not considered as critical for the analysis. On the other hand, the Synergi Polar RP column at buffer pH 5 appears in the upper right part of the score plot providing high Rs values for the following pairs: ivabradine-impurity VIII, impurity IVimpurity $X_{1}$, impurity VIII-impurity $X_{1}$, impurity IV-impurity $X_{2}$, impurity $I X$-impurity $X_{1}$, ivabradine-impurity $X_{1}$, and impurity VIII-impurity $\mathrm{X}_{2}$, out of which only ivabradine-impurity VIII was considered as a critical pair. Further, in the lower left quadrant of the score plot, the Eclipse Phenyl column at $\mathrm{pH} \mathrm{3,} \mathrm{the} \mathrm{Eclipse} \mathrm{Plus} \mathrm{C} 18$ column at $\mathrm{pH} 5$, and

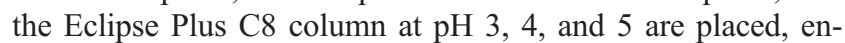
abling adequate separation of ivabradine and impurity IX. The Eclipse Plus $\mathrm{C} 18$ column at $\mathrm{pH} 3$ and 4, as well as the Synergi Polar RP column at $\mathrm{pH} 3$ and 4 placed in the upper left quadrant of the score plot provided the high Rs factor values with the following critical pairs: ivabradine-impurity IV, impurity III-impurity VI, impurity III-impurity V, impurity IX-impurity VIII, impurity IX-impurity IV, and impurity IV-impurity VIII. To sum up, the decision about a proper column was based on the high Rs values for the aforementioned critical pairs. Columns placed in the upper left quadrant managed to resolve a vast majority of the critical pairs. Eventually, from among these columns, the Eclipse Plus C18 column was selected, since under the different buffer $\mathrm{pH}$ values, it enabled separation of ivabradine and impurity IX as well.
BBD and Desirability Function in Optimization of Chromatographic Parameters. According to preliminary experiments and the results of PCA, the significant chromatographic variables and their domains were established and presented in Table 2 .

From a considered list of the organic modifiers, acetonitrile was chosen as one of the most efficient organic modifiers used in RP-HPLC. Potassium phosphate buffer $\left(\mathrm{KH}_{2} \mathrm{PO}_{4}\right)$ was used as the aqueous component of the mobile phase, in order to additionally improve peak symmetries and to adjust the $\mathrm{pH}$ values within the defined domains. The appropriate $\mathrm{pH}$ value and the molarity of the buffer, as well as its influence on the retention, were estimated with the aid of BBD. The PCA responses provided an insight into the retention behavior of the analytes and suggested widening of the $\mathrm{pH}$ range from 4 to 6 . The last variable that could influence not only the retention but also the separation was the column temperature, so it was also included in the BBD.

Though the analytes are of similar polarity and the mixture includes three positional isomers, keto-enol tautomers and 2 diastereoisomers, it was decided to check a possibility of separation in the isocratic elution mode. This decision was quite reasonable bearing in mind simpler retention mechanisms in the isocratic elution mode, reproducible results, and no ghost peaks.

BBD was conducted according to the experimental plan presented in Table 3. The selected responses were resolutions between the adjacent peaks, taking into consideration all critical peak pairs. Those were resolutions between impurities I and XI, III and V, V and VI, III and VI, IX and VIII, IX and $\mathrm{X}_{2}$, IX and IV, IV and VIII, IV and $\mathrm{X}_{1}$, and IV and $\mathrm{X}_{2}$, as well as resolutions between ivabradine and impurities $\mathrm{X}_{1}$ and $\mathrm{X}_{2}$. Resolutions obtained according to experimental plan for 


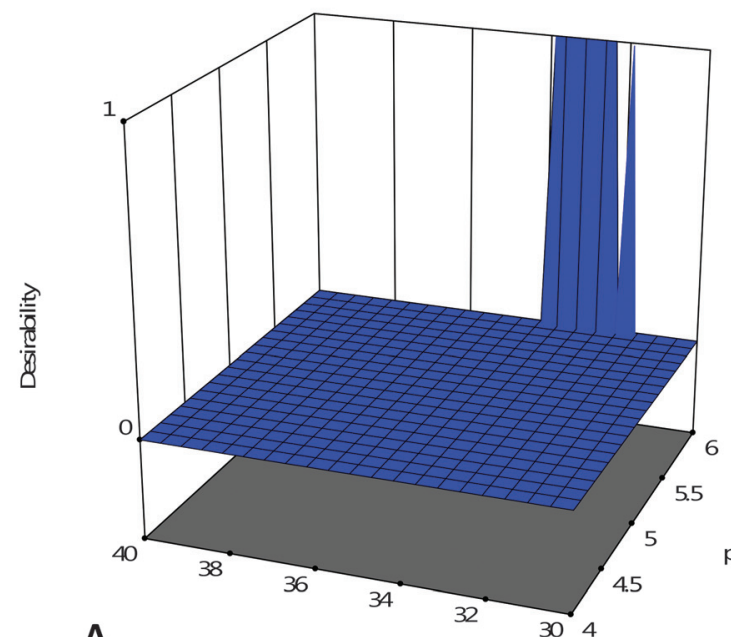

A Temp of the column (deg C)

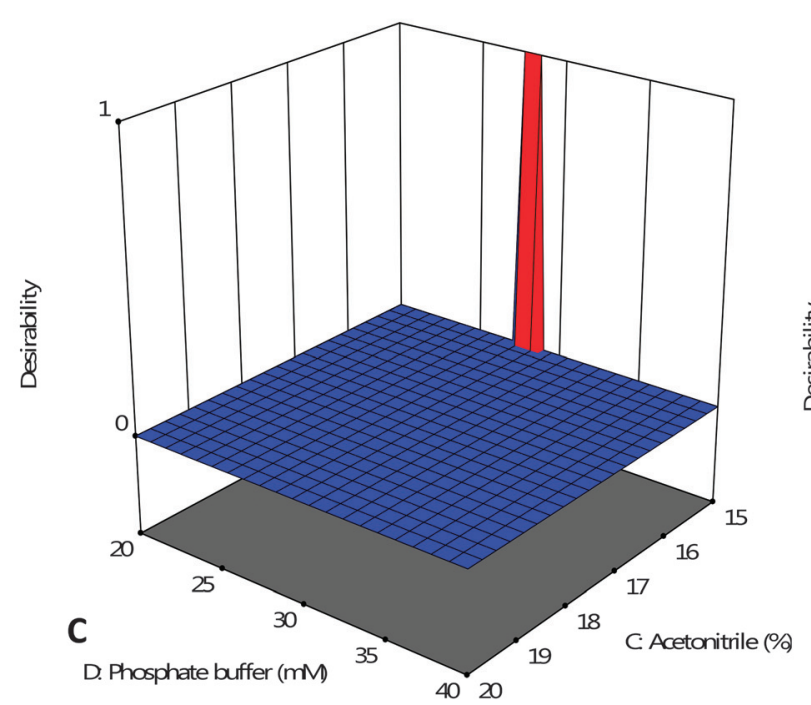

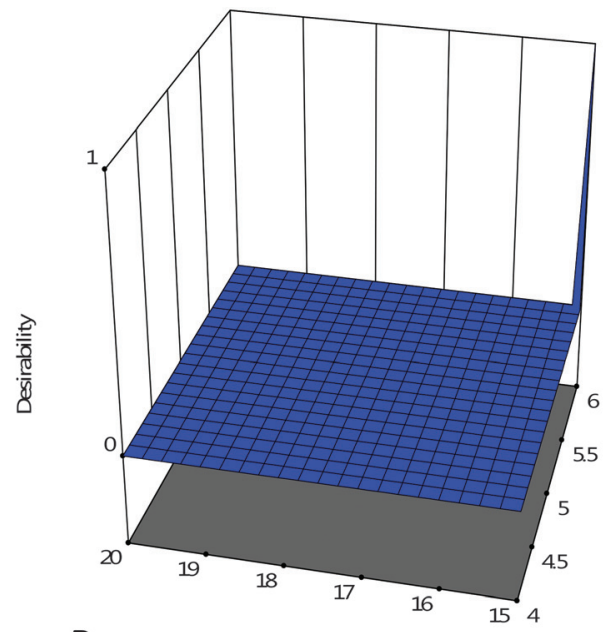

pHvalue
B

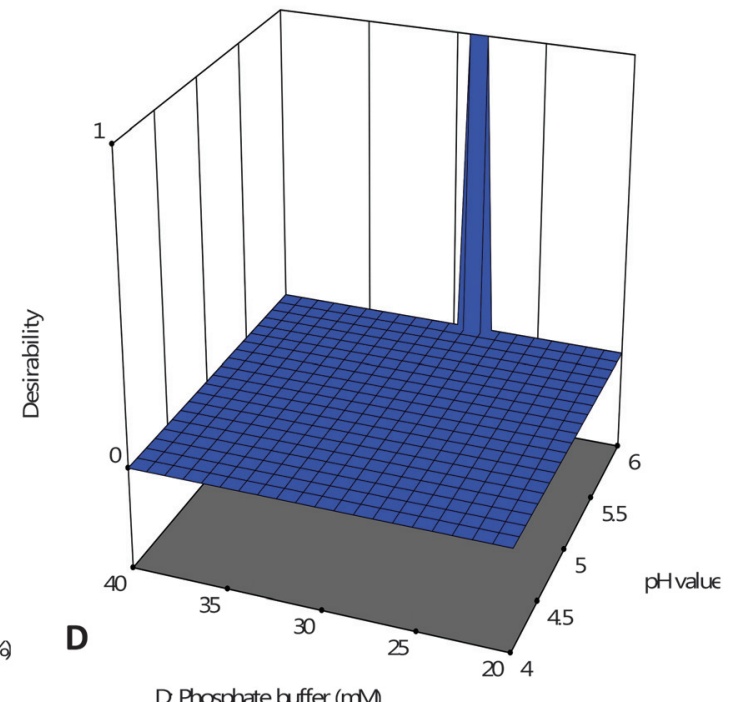

Figure 5. The 3D response surface plots of the overall desirability function (D) for optimization of $\mathrm{pH}$ and the column temperature (A), $\mathrm{pH}$ and acetonitrile (B), acetonitrile and the phosphate buffer molarity (C), and $\mathrm{pH}$ and the phosphate buffer molarity towards the proposed goals

all 12 critical peak pairs are presented in Table 3. For 11 responses, the software proposed the quadratic mathematical models and, only for Rs between impurities IV and VIII, the linear mathematical model. Coefficients of these mathematical models along with their corresponding $p$-values are presented in Table 4. The larger the absolute value of the coefficient, the higher the influence of the variable towards the response. If the coefficients are positive, an increase in the variable influences the increase in the response value and vice versa. On the contrary, if the coefficients are negative, an increase in the variable influences the decrease in the response value. Nevertheless, statistical significance of the variables is estimated using the corresponding $p$-values for all coefficients. Table 4 shows that percentage of organic modifier and $\mathrm{pH}$ of aqueous phase have the highest influence on all responses, while buffer concentration and column temperature appeared less influential, although statistically significant towards most responses. For that reason, all variables were taken into the account in the further optimization process. The validity of all models was confirmed by a nonsignificant lack of the fit test values and high values of the coefficient of determination. Coefficient of determination $\left(R^{2}\right)$, the adjusted $R^{2}$, and the predicted $\mathrm{R}^{2}$ values were above 0.885 pointing out to a good predictive ability of the models and to their ability to explain more than $88 \%$ total variance.
Models with the confirmed validity and predictive ability were used in the multicriteria optimization process. The optimization criteria included the response bounds, the aims for all responses, and the defined weights and importance. The same values of weights and importance equal to 1 were set for all the responses, since all resolutions were of the same interest and their threshold was equal to or higher than 2 . The response bounds were set from the lowest to the highest values of the obtained resolutions, and the overall criteria were in the range from 2 to the highest possible value. All these criteria are presented in Figure 4. For 2 resolutions, those between impurities III and V and IX and VIII, no experimental conditions in the defined experimental range could allow an adequate separation and the resolution factor higher than 2, so that for a while, these resolutions were left out from the optimization process, and no criteria were defined for them. For all the remaining responses, the software offered 23 solutions, and from which, solution 6 was selected. Solution 6 was the only one enabling the highest resolutions for the critical peak pairs between impurities III and V, and IX and VIII. In Figure 4, the obtained resolutions for all 12 critical peak pairs are presented. The optimal chromatographic conditions included the $28 \mathrm{mM}$ phosphate buffer at $\mathrm{pH} 6,15 \%$ acetonitrile in mobile phase, and the column temperature of $34{ }^{\circ} \mathrm{C}$. To gain a better insight into the system behavior and an adequacy of the selected optimal chromatographic conditions, the $3 \mathrm{D}$ plots of the 

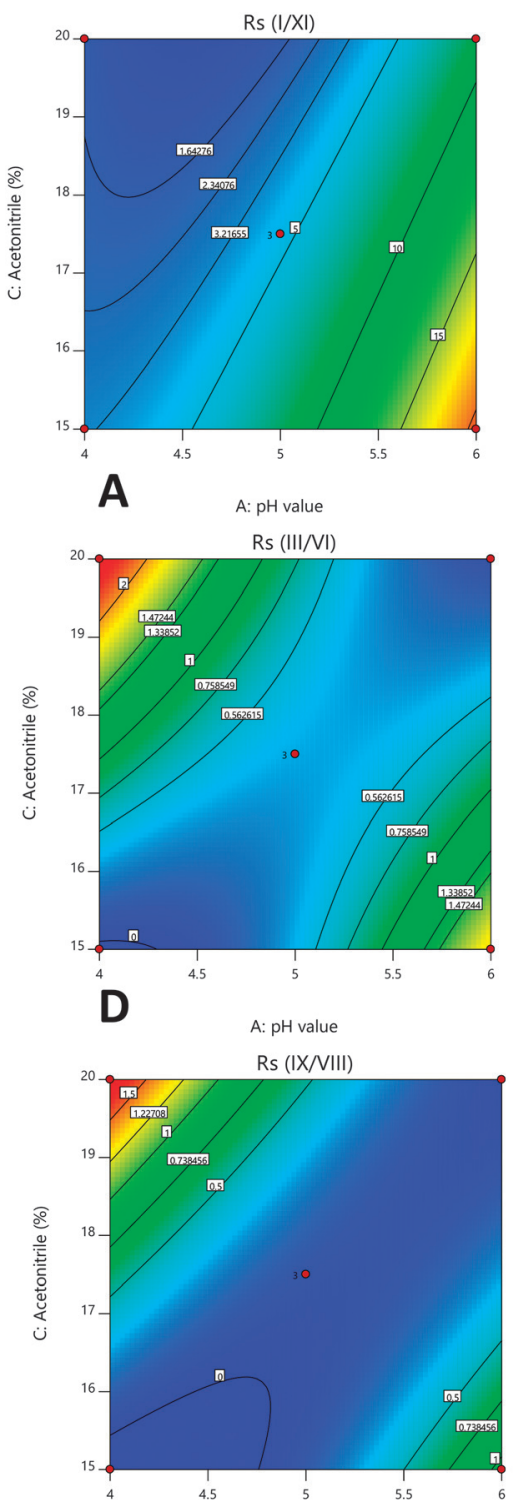

G

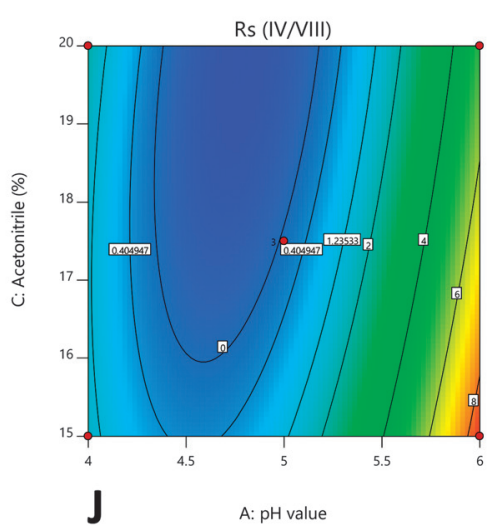

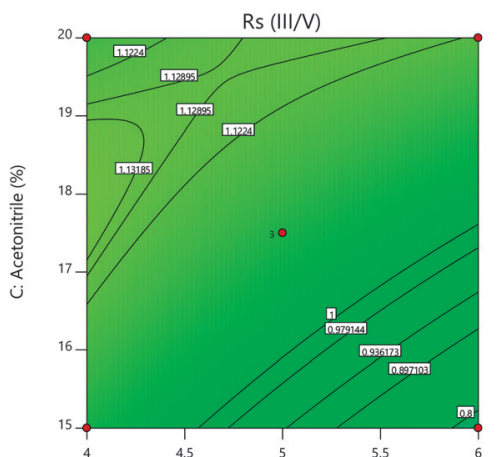

B A: pH value

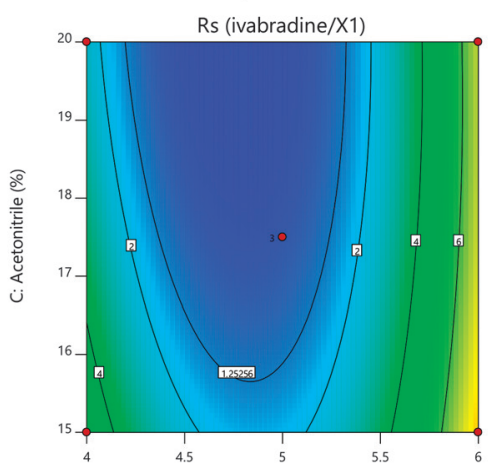

E

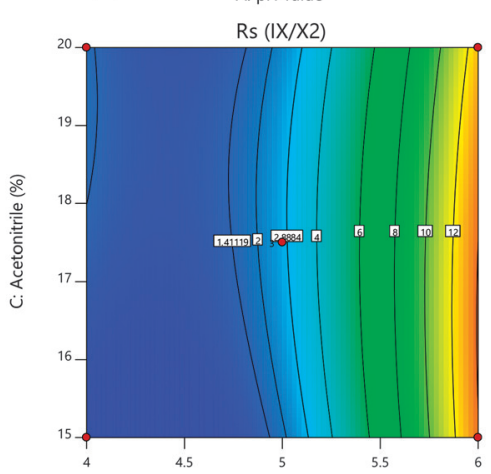

H A: pH value

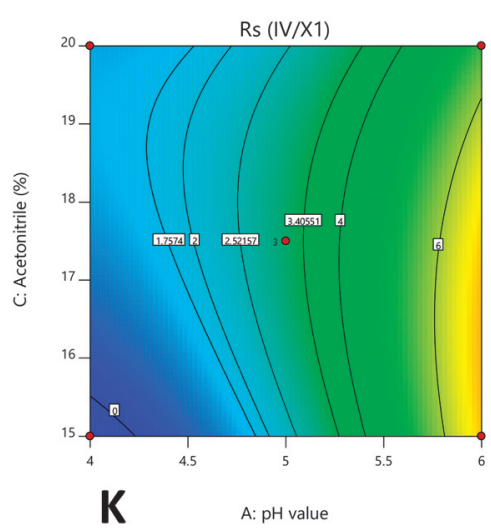

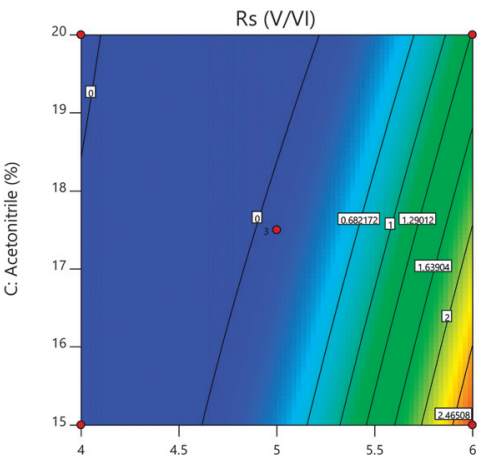

C A: pH value

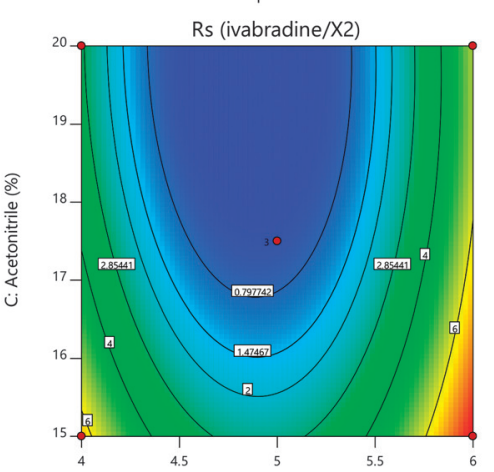

F

$\mathrm{A}: \mathrm{pH}$ value

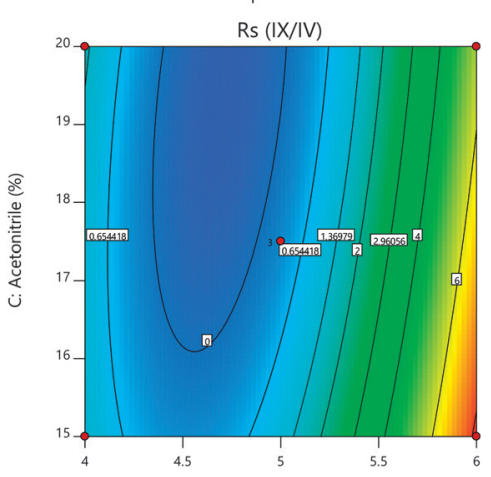

I A: pH value

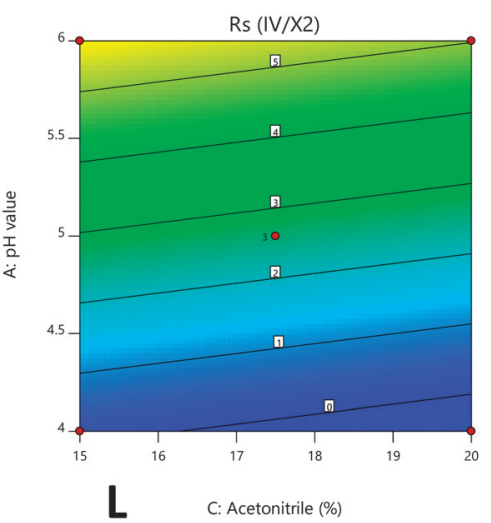

Figure 6. Contour plots that represents the influence of $\mathrm{pH}$ values and content of acetonitrile towards resolution of (A) impurities I and XI, (B) impurities III and V, (C) impurities V and VI, (D) impurities III and VI, (E) ivabradine and impurity $\mathrm{X}_{1}$, (F) ivabradine and impurity $\mathrm{X}_{2},(\mathrm{G})$ impurities IX and VIII, (H) impurities IX and $\mathrm{X}_{2}$, (I) impurities IX and IV, (J) impurities IV and VIII, (K) impurities IV and $\mathrm{X}_{1}$, (L) impurities IV and $\mathrm{X}_{2}$

global desirability function were presented in Figure 5. Detailed assessment of the 3D response surface plot pointed out that $\mathrm{pH} 6$ of aqueous component of the mobile phase and $15 \%$ acetonitrile were the only preconditions which secured the satisfactory optimization criteria. On the contrary, the molarity of the buffer could differ from 26 to $29 \mathrm{mM}$ (Figures 5C and 5D), and the column temperature could differ from 32 to $34{ }^{\circ} \mathrm{C}$ (Figure 5A). In order to obtain better insight into the influence of $\mathrm{pH}$ values and amount of acetonitrile, as the most significant variables, contour plots of these variables towards all critical peak pears are presented in Figure 6. Contour plots indicated that bounder $\mathrm{pH}$ values such as 4 and 6 enabled separation of critical peak pears. Moreover, satisfactory separation of impurities III and V, and IX and VIII could 


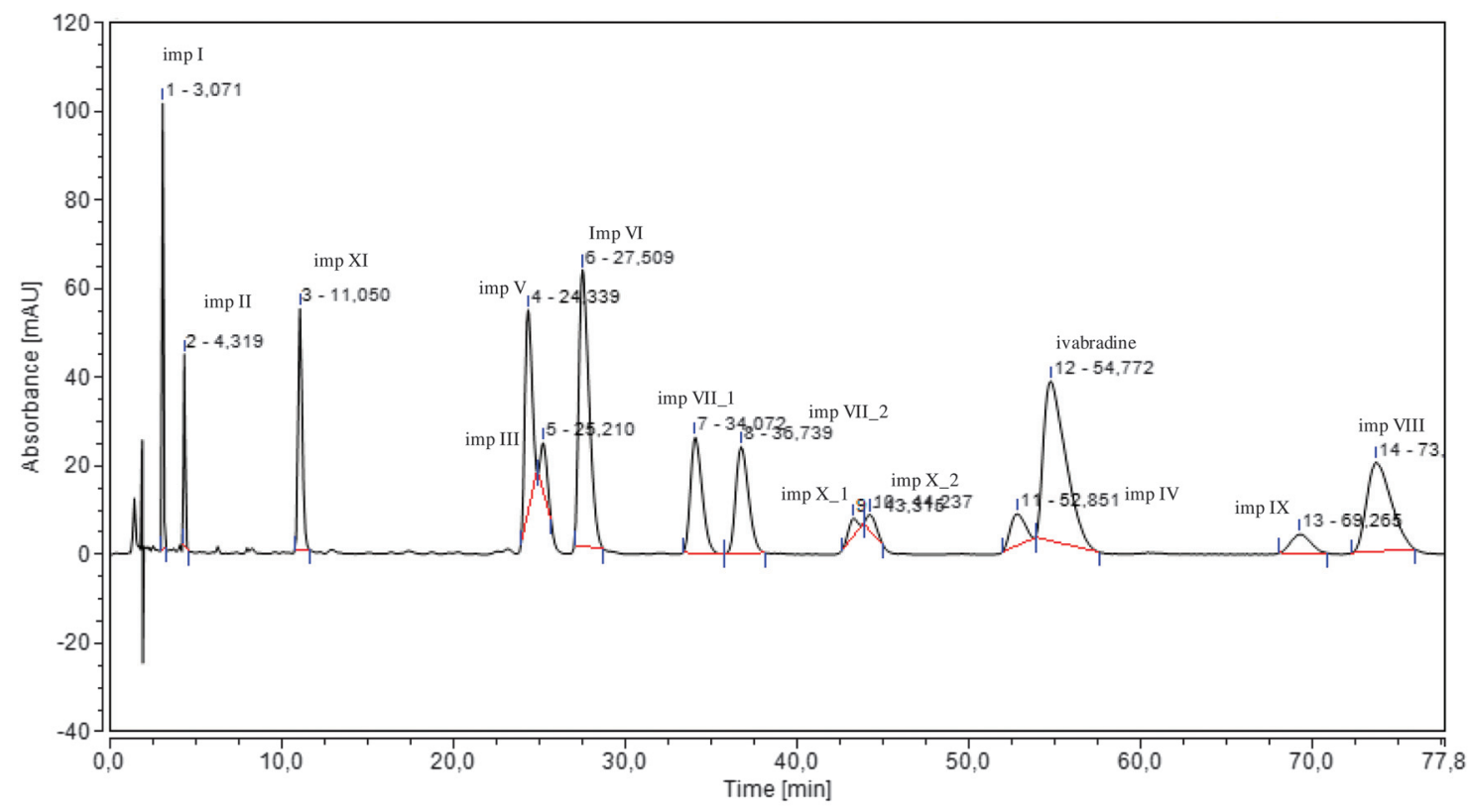

A

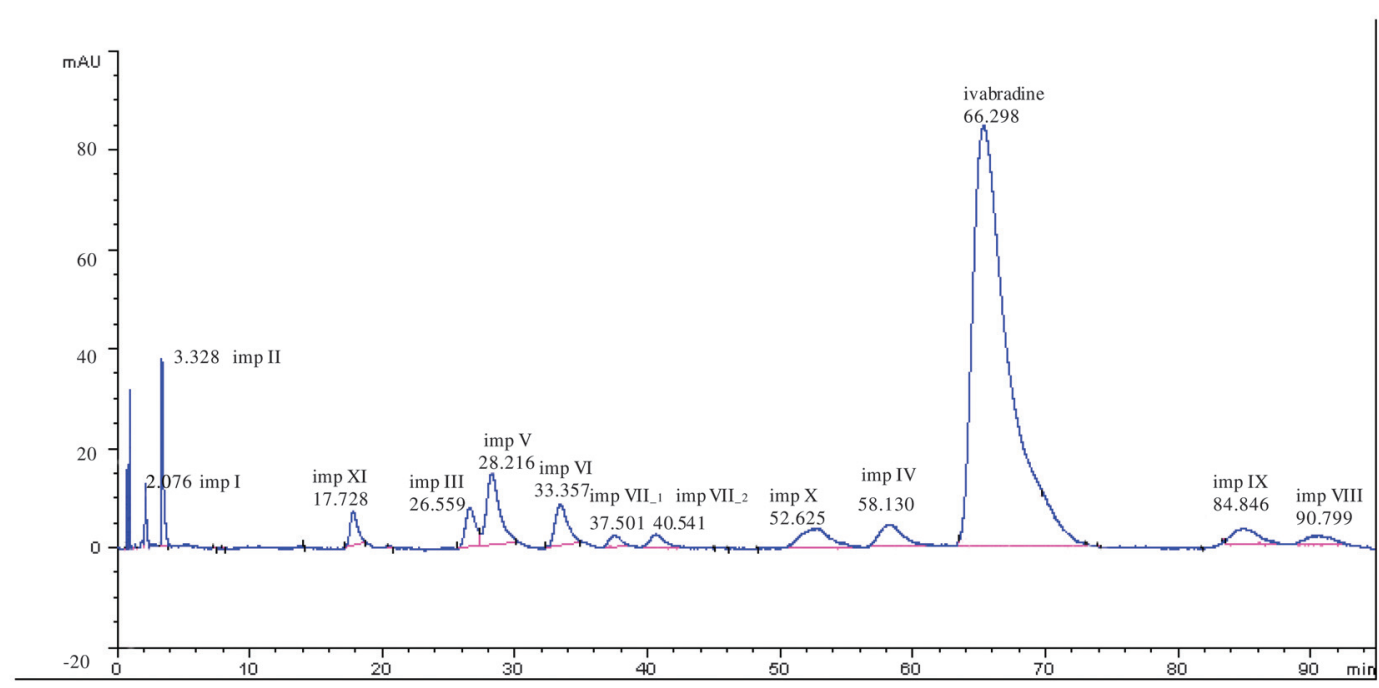

B

Figure 7. Representative chromatogram of ivabradine (ca. $200 \mu \mathrm{g} / \mathrm{mL}$ ) mixed with eleven impurities (ca. $4 \mu \mathrm{g} / \mathrm{mL}$ each), obtained under the proposed chromatographic conditions using the desirability function (A), Representative chromatogram of ivabradine (ca. $200 \mu \mathrm{g} / \mathrm{mL}$ ) mixed with eleven impurities (ca. $4 \mu \mathrm{g} / \mathrm{mL}$ each) obtained under the optimal chromatographic conditions (B)

be achieved at $\mathrm{pH} 4$ with acetonitrile content in the mobile phase close to $20 \%$. However, these chromatographic conditions are unacceptable for other critical resolutions, and consequently desirability function defined $\mathrm{pH} 4$ and acetonitrile content of $20 \%$ as undesirable.

The representative chromatogram obtained under the optimal chromatographic conditions is presented in Figure 7A. According to the expectations, resolution between impurities III and V and IX and VIII did not fulfill the separation requirements, and a consecutive study was necessary. It is important to note that the criteria for Rs differ, depending on the type of the analyte investigated and the corresponding peak areas. The Rs value above 1.5 could provide the baseline separation of impurities, due to rather small and similar peak areas, while this is not the case, when separating an active substance from the impurities, since their corresponding peak areas are significantly different. A possibility of overlapping between active substance and impurity even exists in the case of perfect peaks' symmetries. Additionally, the peak tailing of active substance can lead to a significant reduction in resolution, most notably in the case when the peak of impurity elutes after the peak of active substance. For this reason, resolution higher than 2 and, in some cases, even 2.5 is required between the peak of active substance and the peak of impurity $[27,28]$. Since separation of 2 critical peak pairs included impurities, the separation criterion was set at Rs of ca 1.5. In that respect, the pair of positional isomers (impurities III and V) remained critical, while impurities IX and VIII were satisfactorily separated with Rs of 1.31. For this reason, methanol as an organic modifier of a lower elution strength was included in the mobile phase as well. Addition of methanol to the organic component of mobile phase led to co-elution of diastereoisomers of impurity $\mathrm{X}$, and the separation of diastereoisomers $\mathrm{X}_{1}$ and $\mathrm{X}_{2}$ could not be achieved. This phenomenon can be related to some physicochemical properties of used organic solvents, methanol, and acetonitrile. When acetonitrile is used as a single organic modifier, its molecules form an adsorbed double layer on the surface of the stationary phase, creating a beneficial surrounding for electrostatic interactions. When methanol is added to the mobile phase, it forms a monolayer on the 
stationary phase surface, and different interactions are occurring [29]. As a consequence, separation of diastereoisomers is lacking, and impurity $\mathrm{X}$ is eluting as one peak. An appropriate ratio of acetonitrile and methanol in the organic part of mobile phase was adjusted using the OFAT approach, since only two variables towards the two responses were left. The percentage of methanol was increased in small increments (1\%), while the percentage of acetonitrile was simultaneously and reciprocally decreased to retain $15 \%$ of the overall organic part of the mobile phase as defined in the optimization process. It was proven that the organic component of mobile phase must be acetonitrile-methanol in the ratio of $41: 49, v / v$. During this process, separation of the critical peak pairs was improved, but the retention time of the chromatographic run was also increased. Furthermore, the amount of the organic phase was decided to be $18 \%$, in order to reduce the duration of the overall chromatographic run time. The representative chromatogram obtained under the chromatographic conditions from the second optimization is presented in Figure 7B.

With respect to all the presented and discussed data, the developed method could be labeled as suitable for the separation of ivabradine and its 11 impurities. Nevertheless, the main drawback of the proposed method is a relatively long run time. For this reason, the authors plan to direct their further work to the development of the gradient elution chromatographic method for the separation of the investigated analytes.

\section{Conclusion}

In this study, we, for the first time, presented a chemometrically supported chromatographic method for the separation of ivabradine and its 11 impurities. Based on the PCA results, the Zorbax Eclipse Plus C18 column was chosen as that with optimal selectivity. Additional optimal chromatographic conditions selected using BBD and the desirability function towards 12 critical peak pairs included the $28 \mathrm{mM}$ phosphate buffer at $\mathrm{pH}=6.0$, the column temperature $34{ }^{\circ} \mathrm{C}$, and $15 \%$ acetonitrile in the mobile phase. The mobile phase flow rate was set to $1.6 \mathrm{~mL} \mathrm{~min}{ }^{-1}$. The first assessed separation conditions did not manage to adequately resolve the positional isomers. For this reason, a small increment of methanol was added to the organic part of mobile phase, with an optimal ratio of methanol to acetonitrile equal to $59: 41, v / v$. The overall organic part of mobile phase was increased to $18 \%$, in order to accelerate chromatographic analysis.

\section{Abbreviations}

RP-HPLC: reversed-phase high-performance liquid chromatography, UHPLC: ultra-high-performance liquid chromatography, HPTLC: high-performance thin-layer chromatography, PCA: principal component analysis, PC: principal components, BBD: Box-Behnken design, OFAT: One Factor at a Time, MCDM: multicriteria decision making, RSM: response surface methodology, $d_{\mathrm{i}}$ : individual desirability functions, $D$ : overall desirability function

\section{Supporting Information}

Electronic Supplementary Material (ESM) on Chemical names of ivabradine and its impurities and the degradation products is available at https://doi.org/10.1556/1326.2019.00659.

Acknowledgement. This work was financially supported by Ministry of Education, Science and Technological Development of Republic of Serbia (project no. 172033).

\section{References}

1. http://www.ema.europa.eu/docs/en_GB/document_library/EPAR_Procedural steps_taken_and_scientific_information_after_authorisation/human $/ 004187$ / WC500208112.pdf [last updated 26.02.19]; European Medicines Agency Ivabradine Anpharma, INN-ivabradine. London: EMA.

2. Francesco, D. D.; Camm, J. A. Drugs. 2004, 64, 1757.

3. Sulfi, S.; Timmis, A. D. Int. J. Clin. Pract. 2006, 60, 222.

4. Tse, S.; Mazzola, N. P. T. 2015, 40, 810.

5. Klippert, P.; Jeanniot, J. P.; Polve, S.; Lefevre, C.; Merdjan, H. J. J. Chromatogr. B Biomed. Sci. Appl. 1998, 719, 125.

6. Lu, C.; Jia, Y.; Yang, J.; Jin, X.; Song, Y.; Liu, W.; Ding, Y.; Sun, X.; Wen, A. Acta Pharm. Sin. B. 2012, 2, 205.

7. François-Bouchard, M.; Simonin, G.; Bossant, M. J.; Boursier-Neyret, C. J. Chromatogr. B Biomed. Sci. Appl. 2000, 745, 261.

8. Sun, W.; Chen, R.; Li, W.; Zhang, H.; Ye, J.; Cui, X.; Huang, C. J. Anal. Methods Chem. 2015, 7, 8459.

9. Zoerner, A. A.; Schroeder, C.; Kayacelebi, A. A.; Suchy, M. T.; Gutzki, F. M.; Stichtenoth, D. O.; Tank, J.; Jordan, J.; Tsikas, D. J. Chromatogr. B Analyt. Technol. Biomed. Life Sci. 2013, 927, 105.

10. Damie, M. C.; Bagwe, R. A. Pharm. Sci. Mon. 2015, 6, 141.

11. Maheshwari, S.; Khandhar, A. P.; Jain, A. Eurasian. J. Anal. Chem. 2010; 5,53 .

12. Patel, P. N.; Borkar, R. M.; Kalariya, P. D.; Gangwal, R. P.; Sangamwar,

A. T.; Samanthula, G.; Ragampeta, S. J. Mass Spectrom. 2015, 50, 344.

13. Design Expert 11.0.0. ed, Stat-Ease ${ }^{\circledR}$, Minneapolis, Minnesota, 2018.

14. Statistica $13.5 \mathrm{ed}, T I B C O$ software, California, USA, 2018.

15. Joliffe, T. Principal Components Analysis, Springer, New York, 1986.

16. Wold, S. Chemometr. Intell. Lab. Syst. 1987, 2, 37.

17. Vandeginste, B. G. M.; Massart, D. L.; Buydens, L. M. C.; De Jong, S.; Lewi, P. J; Smeyers-Verbeke, J. Handbook of Chemometrics and Qualimetrics; Part B, Elsevier Amsterdam, 1998, 57.

18. Vandeginste, B. G. M.; Massart, D. L.; Buydens, L. M. C.; De Jong, S.; Lewi, P. J; Smeyers-Verbeke, J. Handbook of Chemometrics and Qualimetrics; Part A, Elsevier Amsterdam, 1997, 519.

19. Pearson, K. Edinb. Dubl. Phil. Mag. Series 6, 1901, $2,559$.

20. Hotteling, H. J. Educ. Psychol. 1933, 24, 417

21. Candioti, L. V.; Robles, J. C.; Mantovani, V. E.; Goicoechea, H. C. Talanta, 2006, 69, 140.

22. Machado, A.; Tejera, E.; Cruz-Monteagudo, M.; Rebelo, I. Eur. J. Med. Chem. 2009, 44, 5045

23. http://www.itl.nist.gov/div898/handbook, 2019 NIST/SEMATECH eHandbook of Statistical Methods.

24. Safa, F.; Hadjmohammadi, M. R. J. Chromatogr. A. 2005, 1078, 42.

25. Ortiz, M. C.; Herrero, A.; Sanllorente, S.; Reguera, C. Talanta, 2005, $65,246$.

26. Jeong, I. J.; Kim, K. J. Eur. J. Oper. Res. 2009, 195, 412.

27. Snyder, L. R.; Kirkland, J. J.; Dolan, J. W. Introduction to Modern Liquid Chromatography, Wiley, 2009.

28. Šljivić, J.; Protić, A.; Malenović, A.; Otašević, B.; Zečević, M. Chromatographia, 2018, 81, 1135.

29. Kazakevich, Y. V.; LoBrutto, R.; Chan, F.; Pate, T.; J. Chromatogr. A. 2001, 913, 75 . 